\title{
Do bleaching gels affect the stability of the masking and caries-arresting effects of caries infiltration-in vitro
}

\author{
Ellen Elisabeth Jansen ${ }^{1}$ (D) $\cdot$ Hendrik Meyer-Lueckel ${ }^{2} \cdot$ Marcella Esteves-Oliveira $^{1,3} \cdot$ Richard Johannes Wierichs $^{2,4}$
}

Received: 9 June 2020 / Accepted: 4 December 2020 / Published online: 14 December 2020

(C) The Author(s) 2020

\begin{abstract}
Objectives The aim of this study was to evaluate the influence of different bleaching gels on the masking and caries-arresting effects of infiltrated and non-infiltrated stained artificial enamel caries lesions.

Materials and methods Bovine enamel specimens $(n=240)$ with each two sound areas (SI and SC) and each two lesions (DI and DC) were infiltrated (DI and SI), stained (1:1 red wine-coffee mixture,70 days), and randomly distributed in six groups to be bleached with the following materials: 6\% HP (HP-6), 16\% CP (CP-16), 35\%HP (HP-35), 40\%HP (HP-40), and no bleaching (NBl,NBl-NBr). Subsequently, specimens were $\mathrm{pH}$-cycled (28 days, $6 \times 60 \mathrm{~min}$ demineralization/day) and all groups except NBl-NBr were brushed with toothpaste slurry $(1.100 \mathrm{ppm}, 2 \times /$ day, $10 \mathrm{~s})$. Differences in colorimetric values $(\Delta L, \Delta E)$ and integrated mineral loss $(\Delta \Delta Z)$ between baseline, infiltration, staining, bleaching, and $\mathrm{pH}$ cycling were calculated using photographic and transversal microradiographic images.

Results At baseline, significant visible color differences between DI and SC were observed ( $\Delta E_{\text {baseline }}=12.2 ; p<0.001$; ANCOVA). After infiltration, these differences decreased significantly $\left(\Delta E_{\text {infiltration }}=3.8 ; p<0.001\right)$. Staining decreased and bleaching increased $\Delta L$ values significantly $(p \leq 0.001)$. No significant difference in $\Delta \Delta E$ was observed between before staining and after bleaching $\left(\Delta E_{\text {bleaching }}=4.3 ; p=0.308\right)$ and between the bleaching agents $(p=1.000 ;$ ANCOVA). pH-cycling did not affect colorimetric values $\left(\Delta E_{\mathrm{pH} \text {-cycling }}=4.0 ; p=1.000\right)$. For DI, no significant change in $\Delta Z$ during in vitro period was observed $(p \geq 0.063$; paired $t$ test).

Conclusions Under the conditions chosen, the tested materials could satisfactorily bleach infiltrated and non-infiltrated stained enamel. Furthermore, bleaching did not affect the caries-arresting effect of the infiltration.

Clinical relevance The present study indicates that bleaching is a viable way to satisfactorily recover the appearance of discolored sound enamel and infiltrated lesions.
\end{abstract}

Keywords Bleaching $\cdot$ Demineralization $\cdot$ Aesthetics $\cdot$ Enamel $\cdot$ White spot lesions $\cdot$ Staining $\cdot$ Caries infiltration $\cdot$ In vitro

Ellen Elisabeth Jansen

ejansen@ukaachen.de

1 Clinic for Operative Dentistry, Periodontology and Preventive Dentistry, RWTH Aachen University, Pauwelsstraße 30, 52074 Aachen, Germany

2 Department of Restorative, Preventive and Pediatric Dentistry, University of Bern, Freiburgstrasse 7, 3010 Bern, Switzerland

3 Department of Cariology, Endodontology and Periodontology, University of Leipzig, Liebigstraße 12, 04103 Leipzig, Germany

4 Department of Biohybrid \& Medical Textiles, Institute of Applied Medical Engineering, RWTH Aachen University, Forckenbeckstraße 55, 52074 Aachen, Germany

\section{Introduction}

In recent years, the aesthetic demands for brighter and whiter teeth by patients have increased [1]. As a consequence, dentists often have to deal with extrinsic or intrinsic staining as well as non-cavitated initial lesions - also known as white spot lesions (WSL). The latter frequently being associated with fixed orthodontic treatments [2]. After orthodontic treatments, a WSL prevalence up to $97 \%$ has been reported [2]. Successful masking of a WSL by remineralizing regimes only seems to be related to the severity of lesion. When being slightly visible, initial WSL can often be completely remineralized naturally since fixed elements - increasing the plaque retention - have been removed. By the additional use of fluorides, e.g., in form of fluoride varnish remineralization 
can be increased [3]. However, clearly visible from a social distance, more severe WSL cannot be visually masked naturally and by fluoride alone, but remain visible for life. Thus, for more severe WSL, micro-invasive treatments are indicated.

Resin infiltration technique is one method to mask initial non-cavitated lesions. After removing the less porous pseudointact surface layer of the caries lesion by using $\mathrm{HCl}$, the lesion microporosities are penetrated with a low-viscosity resin [4]. Due to the similar refractive indices (RI) of the resin infiltrant (RI of infiltrant 1.52) compared with apatite (RI = 1.62), light scattering is, thus, reduced and visual color differences to enamel are decreased directly after application. The masking effect has been reported in vitro $[4,5]$ as well as in vivo $[6,7]$. However, in vitro, it could also be observed that after subsequent staining color differences of infiltrated lesions increased relatively when compared to non-infiltrated demineralized or sound surfaces [4]. In a second study, a higher staining susceptibility was observed for infiltrated surfaces when compared to different bonding agents [8]. Although the pre-demineralization procedure of the lesions and the application procedure of the tested agent were not described in the second study, the results of both studies indicated that infiltrated lesions may discolor over time. This, of course, raises the question if the appearance of discolored infiltrated lesions can be recovered or not.

Bleaching of teeth has been shown to be a conservative aesthetic solution with regard to discoloration [9]. Hydrogen peroxide (HP) and carbamide peroxide (CP) have both been used as bleaching agents [9]. Depending on the bleaching technique, concentrations vary between 6 and 40\% [10]. Generally, lower concentrations of $\mathrm{CP}$ are used for at-home bleaching whereas higher concentrations of both $\mathrm{CP}$ and HP are used for in-office bleaching. Although at-home bleaching was preferred by the patients compared with in-office bleaching [11], both techniques can significantly brighten the teeth with extrinsic discoloration [10]. However, until now, it remains unclear if infiltrated non-cavitated initial lesions can be bleached successfully. Only two studies analyzed the bleaching effects on infiltrated non-cavitated initial lesions - one using 16\% CP for at-home bleaching technique [12] and one using 35\% HP in-office bleaching technique [13]. In both studies, no significant difference in the CIE $L^{*} a^{*} b^{*}$ values were observed between infiltrated lesions and sound enamel. However, only one of the two studies analyzed if stained infiltrated lesions can successfully be bleached but the depths of the infiltrated lesions were not reported. Furthermore, none of the studies analyzed if the cariesarresting effect of the infiltrant is affected by bleaching.

The influence of bleaching materials on composite materials is discussed controversially [14-17]. This is based on a large number of different bleaching and composite materials. An increased surface porosity with crack formation in different composite materials after bleaching was observed in one of the cited studies [14]. In another study, this effect could only be observed with highly concentrated bleaching agents $(35 \% \mathrm{CP})$, while bleaching agents with a lower concentration $(10 \% \mathrm{CP})$ did not negatively affect the surface [15]. Further studies indicated, if bleaching materials are used correctly, either high or low-concentration, bleaches will damage the surface structure $[16,17]$. However, if increased surface porosities or cracks can affect the caries-arresting effect of the infiltration remains unclear until now. Thus, the aim of this in vitro study was to evaluate the influence of different hydrogen peroxide (HP) and carbamide peroxide (CP) bleaching gels on the masking effect (primary aim) and the cariesarresting effect (secondary aim) of infiltrated and noninfiltrated stained artificial enamel caries lesions. The null hypotheses were that, firstly, no significant difference in the bleaching effect can be observed between the tested bleaching agents but for all compared with the negative control (no bleaching) and that, secondly, bleaching does not affect the masking and caries-arresting effects of the infiltration.

\section{Materials and methods}

\section{Specimen preparation}

Bovine incisors were extracted from freshly slaughtered cattle (negative BSE test), cleaned, and preserved in $0.08 \%$ thymol. The teeth were separated in 400 enamel blocks $(5 \mathrm{~mm} \times$ $3.5 \mathrm{~mm} \times 3 \mathrm{~mm}$ ) using a diamond band saw (Exakt 300; Exakt Apparatebau, Norderstedt, Germany) [18] under constant water irrigation. The enamel blocks were embedded in epoxy resin (Technovit 4071; Heraeus Kulzer, Hanau, Germany), ground flat, and polished (4000 grit; silicon carbide, Phoenix Alpha, Wirtz-Buehler, Düsseldorf, Germany; Mikroschleifsystem Exakt, Exakt Apparatebau, Norderstedt, Germany). Subsequently, a commercial red acid-resistant varnish was applied to cover two windows of the enamel surface of each specimen (sound/positive control area (SC) and sound infiltrated area (SI)) (Fig. 1).

\section{Baseline}

To create artificial enamel caries lesions with pseudo-intact surface in the uncovered areas (demineralized/negative $c$ ontrol area (DC) and demineralized infiltrated area (DI)), specimens were stored in a demineralization solution $(2.5 \mathrm{ml}$ solution $/ \mathrm{mm}^{2}$ enamel surface) [19]. The solution contained $50 \mathrm{mM}$ acetic acid, $3 \mathrm{mM} \mathrm{CaCl}_{2}, 3 \mathrm{mM} \mathrm{KH}_{2} \mathrm{PO}_{4}, 6 \mu \mathrm{M}$ methylhydroxydiphosphonate, and traces of thymol $(\mathrm{pH}$ $4.95 ; 37^{\circ} \mathrm{C}$ ). During that period, the $\mathrm{pH}$ was monitored daily. If necessary, it was adjusted with small amounts of either $10 \%$ $\mathrm{HCl}$ or $10 \mathrm{M} \mathrm{KOH}$ to maintain a constant $\mathrm{pH}$ value. The nail 


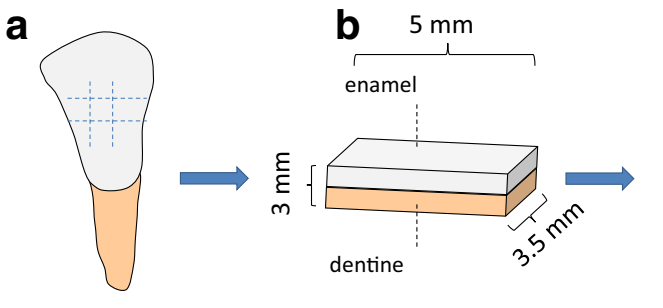

bovine tooth

i

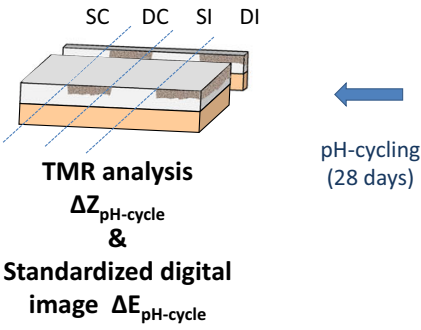

Fig. 1 Specimen preparation. (a) Frontal view of a bovine incisor and lines for cutting perpendicular and parallel to the long axis of the tooth crown; (b) Prepared specimens $(5 \mathrm{~mm} \times 3 \mathrm{~mm} \times 3.5 \mathrm{~mm})$; (c) Specimen covered with acid resistant nail varnish; (d) Pre-demineralized specimen; (e) Preparation of the $100-\mu \mathrm{m}$ slices for baseline TMR analysis (sound/

polish was then carefully removed using cotton pellets and acetone. The other surfaces were protected with a liquid rubber dam. At the end, 240 specimens with a mean (95\% confidence interval $(\mathrm{CI}))$ baseline mineral loss $\left(\Delta Z_{\text {baseline, DI }}\right)$ of $4067(3771 ; 4361)$ vol\% $\times \mu \mathrm{m}$ and lesion depth $\left(\mathrm{LD}_{\text {baseline, }}\right.$ DI) of $171.2(163.2 ; 178.8) \mu \mathrm{m}$ were chosen from the 400 specimens originally prepared [20]. The respective colorimetric values for surface DI were $76.8(76.2 ; 77.5)$ for $L^{*},-4.6$ ($4.8 ;-4.4)$ for $a^{*}$ and $-3.5(-3.8 ;-3.2)$ for $b^{*}$.

\section{Power calculation}

The number of specimens per group was calculated on the basis of a previous study [5]. The $\alpha$-error was set at $5 \%$. Since for the retrospective power analysis with 38 specimens per group has still provided a power of at least $100 \%$ for the comparison between time points $\Delta E_{\text {baseline }}$ and $\Delta E_{\text {infiltration, }}$ the comparison between $\Delta E_{\text {baseline }}$ and $\Delta E_{\mathrm{pH} \text {-cycle }}$ and the comparison between $\Delta E_{\text {baseline }}$ and $\Delta E_{\mathrm{pH}-\mathrm{cycle}}$, no additional specimens were involved in the study.

\section{Infiltration}

Icon ${ }^{\circledR}$ (DMG, Hamburg, Germany) was applied according to the manufacturer's instructions, and only the etching procedure was adapted to the bovine teeth. For $5 \mathrm{~s}$, DI and SI were etched using 37\% phosphoric acid gel (Total Etch; Vivadent, Schaan, Liechtenstein) (instead $120 \mathrm{~s}$ using $\mathrm{HCl}$ as instructed) $[4,21]$. Subsequently, the acid gel was removed with distilled water for $30 \mathrm{~s}$. Then, the surface was dried using Icon Dry ${ }^{\circledR}$ d $\quad$ e

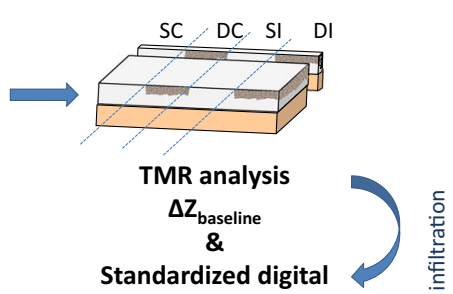

f image $\Delta \mathrm{E}_{\text {baseline }}$

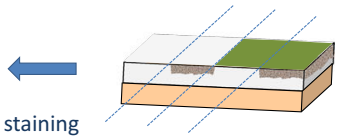

Standardized digital image $\Delta \mathrm{E}_{\text {infiltration }}$

positive control area (SC), demineralized infiltrated area (DI); sound $i$ nfiltrated area (SI) and demineralized/negative control area (DC)); (f) Infiltrated specimen (green, only DI and SI); (g) Stained specimen (black); (h) Bleached specimen (gray); (i) Preparation of the $100-\mu \mathrm{m}$ slices for TMR analysis after $\mathrm{pH}$-cycling

for $30 \mathrm{~s}$ and infiltrated using Icon Infiltrant ${ }^{\circledR}$ for $3 \mathrm{~min}$. Subsequently, excess material was carefully removed by means of cotton pellets, and the resin was light-cured for 40 s. The application of Icon Infiltrant ${ }^{\circledR}$ was repeated $(1 \mathrm{~min})$ and light-cured again (40 s) [5]. After the application the treated surface was polished as recommended by the manufacturer. For this, a polishing cup (Pro-Cup Soft-Light Blue, Kerr, Biberach, Germany) was used.

\section{Staining}

The specimens were stored in a remineralization solution for 70 days $[4,8,22]$. During this period once daily for $10 \mathrm{~min}$, all specimens were immersed once daily for $10 \mathrm{~min}$ in a 1:1 mixture of red wine (Flamand Rouge, Edeka, Hamburg, Germany) and coffee infusion ( $25 \mathrm{~g}$ of powder to $250 \mathrm{~mL}$ of water; Nescafe Gold, Nestlé, Frankfurt, Germany) Thus, extrinsic dietary staining was simulated.

\section{Bleaching}

The specimens were randomly divided into 6 groups each. Over a period of 10 days before the $\mathrm{pH}$-cycling, specimens were treated with the respective bleaching materials:

- $\quad$ o bleaching, no brushing (NBl-NBr)

- no bleaching, but brushing (NBl)

- $6 \%$ hydrogen peroxide bleaching gel for at-home bleaching technique ( $\mathrm{pH}$ 4.6-6.6; Opalescence Go 6\%, 
Ultradent Products, South Jordan, Utah, USA) and brushing (HP-6)

- $16 \%$ carbamide peroxide gel for at-home bleaching technique ( $\mathrm{pH}$ 6.0-7.2; Opalescence PF 16\%, Ultradent Products) and brushing (CP-16)

- $35 \%$ hydrogen peroxide bleaching gel for in-office bleaching technique ( $\mathrm{pH}$ 5.6-6.9 [23]; HP AutoMixx $35 \%$, FGM, Joinville, SC, Brazil) and brushing (HP-35)

- $40 \%$ hydrogen peroxide bleaching gel for in-office bleaching technique (pH 6.0-8.5; Opalescence Extra Boost, Ultradent Products) and brushing (HP-40)

Specimens of NBl-NBr and NBl were stored in distilled water all the time.

Specimens of HP- 6 and CP- 16 were covered with a layer of approximate $1 \mathrm{~mm}$ of the bleaching gel for $8 \mathrm{~h}$ in a humid atmosphere at $37^{\circ} \mathrm{C}$ once daily. Furthermore, the specimens were stored in distilled water in the remaining time $\left(37^{\circ} \mathrm{C}\right)$ [24]. To not affect the results by differing application times, the specimens in both groups were bleached according to the same protocol [24]. Specimens of HP-40 and HP-35 were treated twice on two days (day 1 and day 5) at 7-h intervals. For this purpose, the specimens were covered with a layer of $1 \mathrm{~mm}$ of bleaching gels for $30 \mathrm{~min}$ at room temperature. In the time between the treatments, the specimens were stored in distilled water $\left(37^{\circ} \mathrm{C}\right)[24]$. To not affect the results by differing application times, the specimens in both groups were bleached according to the same protocol [24].

Prior to bleaching, the surfaces were dried with cotton wool pellets. After treatment and before retransferring to the distilled water, the bleaching agents were carefully removed by rinsing with distilled water for $30 \mathrm{~s}$.

\section{pH-cycling}

pH-cycling started right after bleaching. For this, a computercontrolled $\mathrm{pH}$-cycling and brushing machine [5] was used to simulate oral $\mathrm{pH}$-fluctuation patterns and daily tooth brushing for 28 days. The $\mathrm{pH}$-cycling involved 6 demineralization periods of $1 \mathrm{~h}$ each (total $6 \mathrm{~h} /$ day) and 6 remineralization periods of at least $2 \mathrm{~h}$ during the day and a longer overnight period (total $18 \mathrm{~h} /$ day). The remineralization solution contained $1.5 \mathrm{mM} \mathrm{CaCl}_{2}, 0.9 \mathrm{mM} \mathrm{KH}_{2} \mathrm{PO}_{4}$, and $20 \mathrm{mM} \mathrm{N}-2$ hydroxyethylpiperazine-N'2-ethanesulfonic acid (HEPES) as buffer, $\mathrm{pH} 7.0\left(37{ }^{\circ} \mathrm{C}\right)$. The demineralization solution contained $6 \mu \mathrm{M}$ methylhydroxydiphosphonate, $3 \mathrm{mM}$ $\mathrm{CaCl}_{2}, 3 \mathrm{mM} \mathrm{KH}_{2} \mathrm{PO}_{4}$, and $50 \mathrm{mM}$ acetic acid adjusted to $\mathrm{pH} 4.87\left(37{ }^{\circ} \mathrm{C}\right)[19]$. The $\mathrm{pH}$-cycling solutions were refreshed with every cycle $(6 \times /$ day $)$. The amounts of each solution were large enough to prevent the solutions from becoming saturated with or depleted of mineral ions $(0.7 \mathrm{ml}$ solution $/ \mathrm{mm}^{2}$ enamel surface). Before the first and last remineralizing phase, specimens of all groups (except NBl-
$\mathrm{NBr}$ ) were brushed for $10 \mathrm{~s}$ (Oral-B Indicator; Proctor \& Gamble, Schwalbach am Taunus, Germany) with a fluoride dentifrice slurry (1100 ppm $\mathrm{F}^{-}$as NaF; Crest Cavity Protection, Proctor \& Gamble, Schwalbach am Taunus, Germany). Dentifrice slurries were prepared with deionized water in a ratio of 1:2 (toothpaste:water) parts by weight and refreshed every two days [25]. The dentifrice slurry remained on each specimen for another $110 \mathrm{~s}$. Subsequently, the specimens were perfused with distilled water to remove the slurry. In total, brushing procedure for each specimen lasted $120 \mathrm{~s}$, hence simulating the recommended brushing time of $2 \mathrm{~min}$. Specimens of group NBl-NBr were not brushed at any time. The machine was adjusted to a constant brushing frequency of 60 strokes/min and a constant brushing load of $1.5 \mathrm{~N}$ [26].

\section{Colorimetric analysis}

Stability, accuracy, and reliability of colorimetric measurements were evaluated as described previously $[4,5]$. Within a lightproof black box and under standardized conditions (aperture of f 45 , shutter speed at $1 / 60 \mathrm{~s}$, and image ISO sensitivity 200), digital photographs of moist specimens were obtained using a fixed SLR camera (Nikon D7000, Nikon, Tokyo, Japan). Images of the specimens with a black background were taken with a macro-lens (Nikon $105 \mathrm{~mm}, 1: 2.8$, Nikon) and a ring flash (Sigma Em-140 DG, Nikon, lightening intensity $1 / 4$, reloaded batteries) at the following instants of times: after pre-demineralization $\left(\Delta E_{\text {baseline }}\right)$, after infiltration ( $\left.\Delta E_{\text {infiltration }}\right)$, after staining $\left(\Delta E_{\text {staining }}\right)$, after bleaching ( $\left.\Delta E_{\text {bleaching }}\right)$, and after pH-cycling $\left(\Delta E_{\mathrm{pH}-\text { cycle }}\right)$. In order to be able to control the standardized conditions, with each specimen, a gray card (Mennon Gray Cards Neutraal $18 \%$; Mennon USA, USA) was photographed.

Evaluation of digital images (RAW-format) was performed using Photoshop CS6 extended (Adobe, San Jose, USA) [5]. For all timepoints, the same area of each specimen was evaluated. The CIE- $L^{*} a^{*} b^{*}$ color system was used to analyze optical results. It records colorimetric parameters three-dimensionally: lightness $\left(L^{*} ; 0\right.$ to +100$)$, green-red chromaticity $\left(a^{*} ;-150\right.$ to +100$)$, and blue-yellow chromaticity $\left(b^{*} ;-\right.$ 100 to +150 ). Within a window of $105 \times 105$ picture elements, the CIE $L^{*} a^{*} b^{*}$ values were measured. For the chosen 240 , the colorimetric values for the surfaces DI, DC, SI, and SC at baseline were as follows: $76.8(76.2 ; 77.5)$ for $L^{*}{ }_{\mathrm{DI}}$, $4.6(-4.8 ;-4.4)$ for $a^{*} \mathrm{DI}$ and $-3.5(-3.8 ;-3.2)$ for $b^{*} \mathrm{DI}$; $79.5(79.0 ; 80.0)$ for $L^{*}{ }_{\mathrm{DC}},-3.9(-4.1 ;-3.7)$ for $a^{*}{ }_{\mathrm{DC}}$ and $1.9(-2.2 ;-1.6)$ for $b^{*}{ }_{\mathrm{DC}} ; 69.3(68.8 ; 69.9)$ for $L^{*}{ }_{\mathrm{SI}},-1.5(-$ $1.7 ;-1.3)$ for $a^{*}{ }_{\mathrm{SI}}$ and $2.4(-2.0 ;-2.9)$ for $b^{*}{ }_{\mathrm{SI}} ; 66.3(66.7$; $66.8)$ for $L^{*} \mathrm{SC},-1.2(-1.4 ;-1.0)$ for $a^{*} \mathrm{SC}$, and $0.9(-0.5 ;-$ 1.2) for $b^{*} \mathrm{SC}$.

Color differences $(\Delta E)$ and variation in lightness $(\Delta L)$ were calculated (Excel 2010, Microsoft, Redwood, USA) using the equation $\Delta E=\left(\left(L_{\text {sound* }}-L_{\text {caries* }}\right)^{2}+\left(b_{\text {sound* }}-\right.\right.$ 
$\left.\left.\mathrm{b}_{\text {caries* }}\right)^{2}+\left(a_{\text {sound* }}-a_{\text {caries** }}\right)^{2}\right)^{1 / 2}$ and $\Delta L=L_{\text {sound* }}-L_{\text {caries* }}$, respectively. Changes in colorimetric values (e.g., $\Delta \Delta E_{3}=$ $\Delta E_{\text {baseline }}-\Delta E_{\text {bleaching }}$ ) were calculated.

\section{Transversal microradiographic analysis}

After pre-demineralization and after $\mathrm{pH}$-cycling, thin planeparallel sections were prepared. Changes in mineral loss ( $\Delta \Delta Z=\Delta Z_{\text {baseline }}-\Delta Z_{\text {pH-cycle }}$ ) were calculated using transversal microradiographic images. Microradiographs of the enamel specimens were obtained and analyzed as described previously $[27,28]$.

\section{Statistical analysis}

Data were analyzed using SPSS statistical software (SPSS 25.0; SPSS, Munich, Germany). Variables were tested for normal distribution (Shapiro-Wilk test). Within one group, changes in mineral loss after pre-demineralization $\left(\Delta Z_{\text {baseline }} / \mathrm{LD}_{\text {baseline }}\right)$ and after $\mathrm{pH}$-cycling $\left(\Delta Z_{\mathrm{pH} \text {-cycle }} / \mathrm{LD}_{\mathrm{pH}-}\right.$ cycle) were analyzed using two-tailed paired $t$ tests. Changes in colorimetric values after pre-demineralization $\left(\Delta E_{\text {baseline }}\right)$, after infiltration $\left(\Delta E_{\text {infiltration }}\right)$, after staining $\left(\Delta E_{\text {staining }}\right)$, after bleaching $\left(\Delta E_{\text {bleaching }}\right)$, and after $\mathrm{pH}$-cycling $\left(\Delta E_{\mathrm{pH} \text {-cycle }}\right)$ within one group were analyzed using analysis of covariance (ANCOVA) and Bonferroni post hoc tests.

Analysis of covariance (ANCOVA) for sound and demineralized surfaces and Bonferroni post hoc tests were also used for pair-wise multiple-comparisons to detect differences in changes of mineral loss $(\Delta \Delta Z)$ and colorimetric values $(\Delta \Delta E)$. More technically the ANCOVA statistical model may be described as a general linear mixed model with transversal microradiographic (TMR)/colorimetric data and treatment as fixed effects. All tests were performed at a 5\% level of significance.

\section{Results}

\section{Colorimetric analysis}

At baseline, significant visible color differences between DI and SC were observed within each group $\left(\Delta E_{\text {baseline }}=12.2 ; p\right.$ $<0.001$; ANCOVA, Table 1, Fig. 2). After infiltration, these differences decreased significantly (Fig. 3$),\left(\Delta E_{\text {infiltration }}=\right.$ $3.8 ; p<0.001 ;$ ANCOVA).

Staining decreased and bleaching increased $\Delta L$ values significantly $(p<0.001)$. For HP-6, CP-16, HP-35, and HP-40, no significant difference in colorimetric values could be observed between before staining and after bleaching $\left(\Delta E_{\text {bleaching }}=4.3 ; p=0.3080\right)$. Furthermore, no significant difference between the bleaching agents was observed $(p=$ 1.000). However, after bleaching, DC was significantly brighter than DI $(p \leq 0.001)$. pH-cycling did not affect colorimetric values $\left(\Delta E_{\mathrm{pH} \text {-cycling }}=4.0 ; p=1.000\right)$.

\section{Transversal microradiographic analysis}

For infiltrated demineralized enamel, no significant change in mineral loss between values after initial demineralization $\left(\Delta Z_{\text {baseline,DI }}(95 \% \mathrm{CI}): 4067(3771 ; 4361) \mathrm{vol} \% \times \mu \mathrm{m}\right)$ and after pH-cycling $\left(\Delta Z_{\mathrm{pH}-\text { cycle,DI }}(95 \% \mathrm{CI}): 3842(3573 ; 4103)\right.$ vol $\% \times \mu \mathrm{m})$ was observed $(p \geq 0.063$; paired $\mathrm{t}$ test). For noninfiltrated demineralized enamel $\left(\Delta Z_{\text {baseline,DC }}(95 \% \mathrm{CI})\right.$ : $4588(4279 ; 4895)$ vol\% $\times \mu \mathrm{m} ; \Delta Z_{\mathrm{pH}-\mathrm{cycle}, \mathrm{DC}}(95 \% \mathrm{CI})$ : $5223(4882 ; 5564)$ vol $\% \times \mu \mathrm{m})$, a significant increase in mineral loss was observed for NBl-NBr as well as for acidic bleaching agents (HP-6r and HP-35) $(p \leq 0.037$, Table 2), whereas no significant increase could be observed for NBl and neutral bleaching agents (CP-16an HP-40) $(p \geq 0.184)$. Furthermore, no significant difference between the groups could be observed for $\Delta \Delta Z_{\mathrm{DC}}(p \geq 0.438$, ANCOVA, Table 2$)$ and $\Delta \Delta Z_{\mathrm{DI}}(p=1.000)$. However, $\Delta \Delta Z_{\mathrm{DC}}$ was significantly higher compared with $\Delta \Delta Z_{\mathrm{DI}}(p<0.001$, paired $t$ test).

\section{Discussion}

The present in vitro study compared the bleaching effects of different hydrogen peroxide and carbamide peroxide bleaching gels on infiltrated and non-infiltrated stained caries-like enamel lesions. Without any material-depending differences, all bleaching agents were able to significantly whiten sound and demineralized enamel when compared to the negative controls (no bleaching). The primary hypothesis was, thus, accepted. Furthermore, no significant differences in the colorimetric values and mineral contents before staining and after bleaching and $\mathrm{pH}$-cycling could be observed, confirming the second hypothesis that bleaching does not affect the masking and caries-arresting effects of the infiltration.

In the present study, staining significantly increased $\Delta E$ values of infiltrated demineralized and infiltrated sound enamel (DI and SI, respectively). $\Delta E$ values of non-infiltrated demineralized enamel remained relatively stable even though they discolored as much as the rest of the specimens. Furthermore, they showed the highest $\Delta E$ values before and after staining, although color differences of infiltrated lesions increased relatively when compared to non-infiltrated demineralized or sound enamel. Furthermore, no significant differences among the three areas could be observed after staining. These results are in agreement with previous studies $[4,12,29]$. In the first study, staining provided a significant reduction of $\Delta L$ values in infiltrated lesions, sound enamel, and in untreated lesions without any differences among the three groups [12]. In the second study, after staining, no 


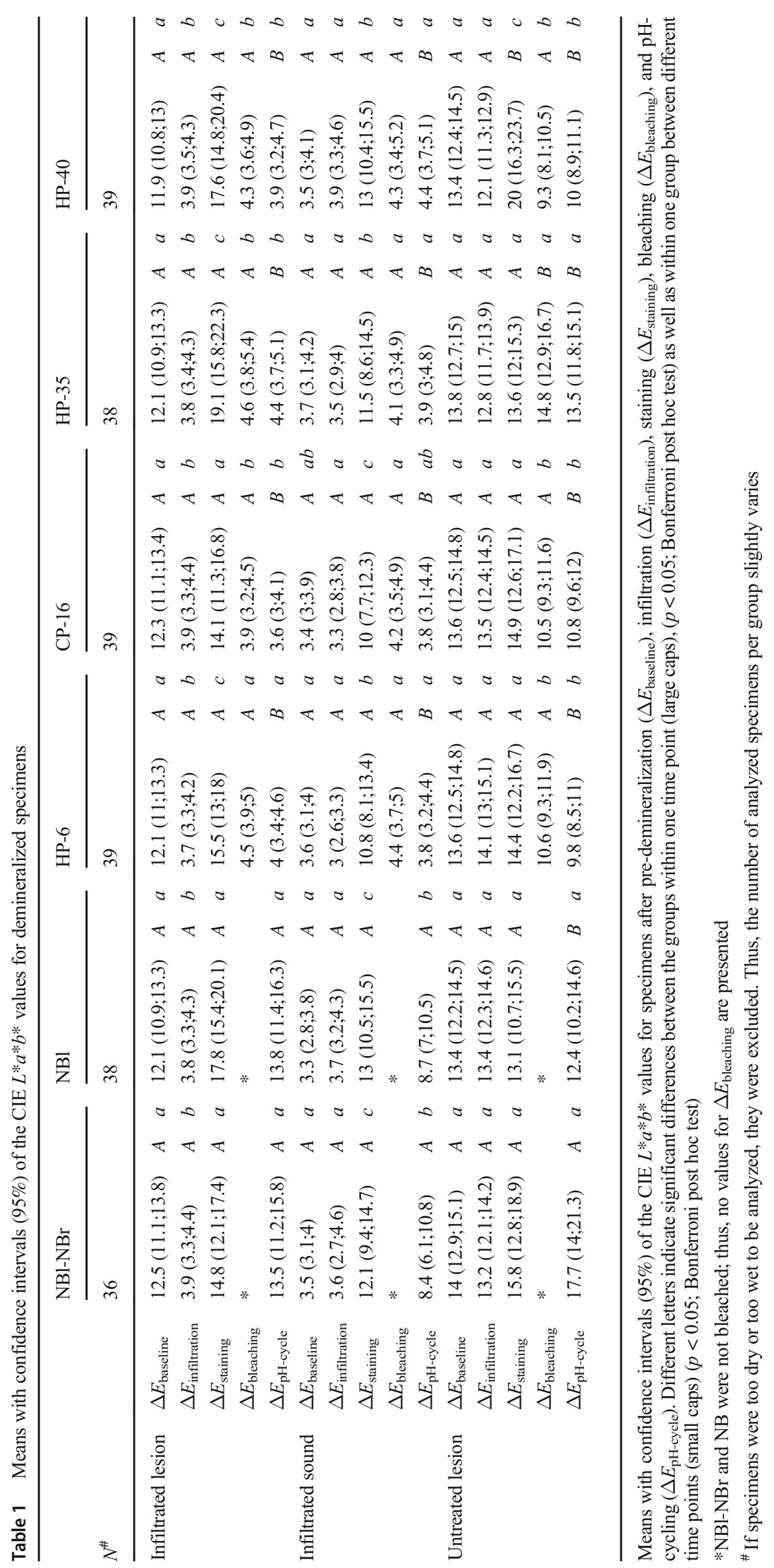


Fig. 2 Means with confidence intervals $(95 \%)$ of colorimetric values $(\Delta E)$ for demineralized specimens at different time points. Colorimetric values of infiltrated demineralized enamel can be seen in a and colorimetric values of infiltrated sound enamel can be seen in b. Different letters indicate significant differences between different time points $(p<$ 0.05 ; Bonferroni post hoc test). Asterisk symbol indicates that $\mathrm{NBl}-\mathrm{NBr}$ and NB were not bleached; thus, no values for $\Delta E_{\text {bleaching }}$ are presented a

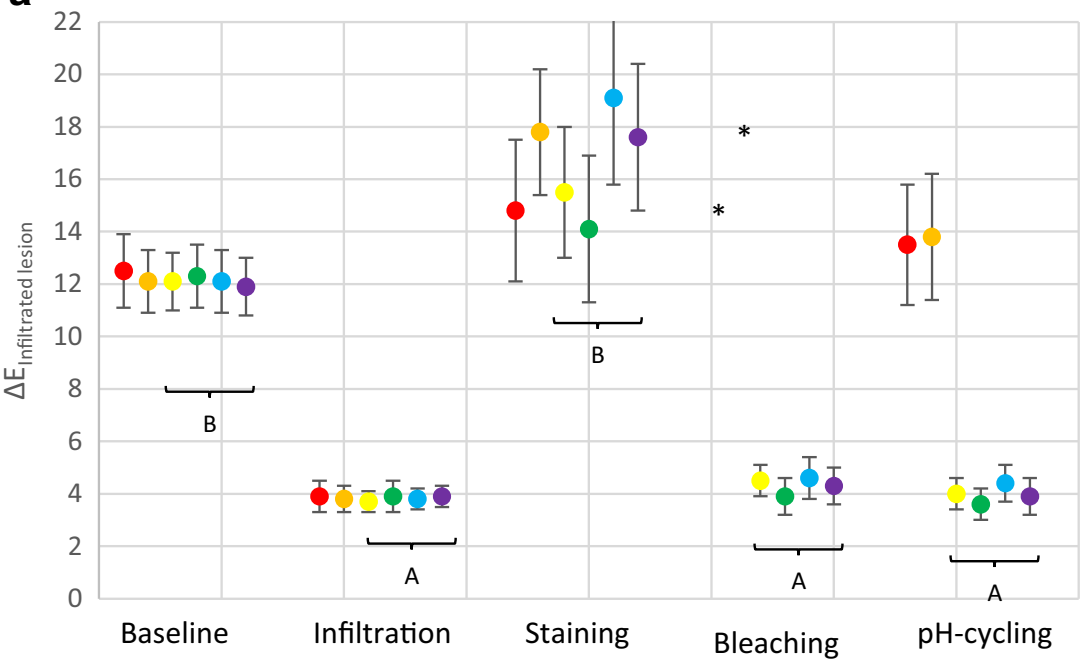

b

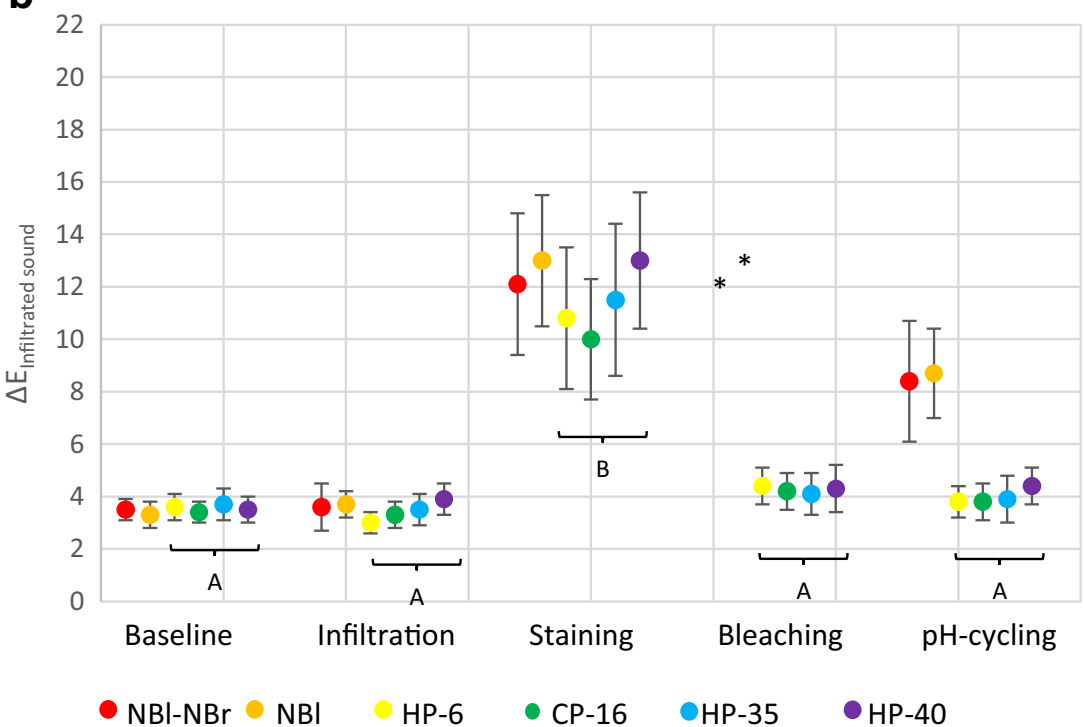

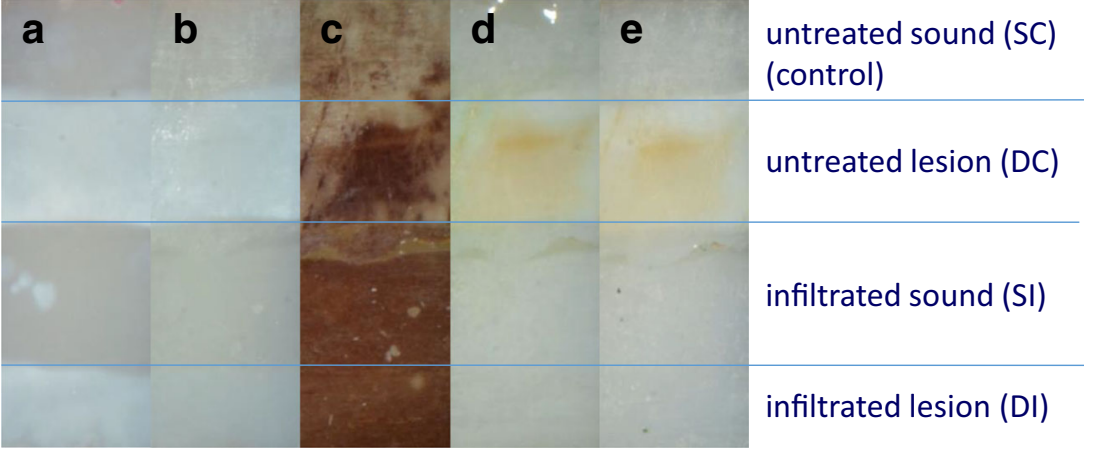

Fig. 3 Photographs of one representative demineralized specimen at different times of treatment: Baseline (a), Infiltration (b), Staining (c), Bleaching (d), and $\mathrm{pH}$-cycle (e). Staining discolored all areas considerably. Bleaching recovered the appearance of discolored sound enamel and infiltrated lesions. After bleaching, infiltrated lesion was visually not discriminable from sound enamel. The results remained stable during pH-cycling 
Table 2 Mean (95\% confidence interval) mineral losses after initial demineralization $\left(\Delta Z_{\text {baseline,DI }} / \Delta Z_{\text {baseline,DC }}\right)$, after $\mathrm{pH}$-cycling $\left(\Delta Z_{\mathrm{pH}-\mathrm{cycling}, \mathrm{DI}} /\right.$ $\Delta Z_{\mathrm{pH} \text {-cycling,DC }}$ ), and changes in mineral loss $\left(\Delta \Delta Z_{\mathrm{DI}} / \Delta \Delta Z_{\mathrm{DC}}\right)$ of demineralized infiltrated (DI) and non-infiltrated (DC) lesions

\begin{tabular}{|c|c|c|c|c|c|c|c|c|c|c|c|}
\hline \multirow{2}{*}{$\begin{array}{l}\text { Intervention } \\
\mathrm{NB} 1-\mathrm{NBr}\end{array}$} & \multirow{2}{*}{$\begin{array}{l}N \\
24\end{array}$} & \multicolumn{3}{|c|}{$\Delta Z_{\text {baseline,DI }}($ vol $\% \times \mu \mathrm{m})$} & \multicolumn{3}{|c|}{$\Delta Z_{\mathrm{pH} \text {-cycling,DI }}(\mathrm{vol} \% \times \mu \mathrm{m})$} & \multirow{2}{*}{$\begin{array}{l}p^{*} \\
0.747\end{array}$} & \multicolumn{2}{|c|}{$\Delta \Delta Z_{\mathrm{DI}}(\operatorname{vol} \% \times \mu \mathrm{m})$} & \\
\hline & & 3785 & $(3188 ; 4382)$ & $A$ & 3718 & $(3158 ; 4279)$ & $A$ & & 106 & $(-354 ; 567)$ & \\
\hline $\mathrm{NBl}$ & 24 & 4111 & $(3248 ; 4975)$ & $A$ & 3744 & $(3072 ; 4416)$ & $A$ & 0.322 & 234 & $(-527 ; 996)$ & \\
\hline HP-6 & 24 & 4636 & $(3785 ; 5487)$ & $A$ & 4455 & $(3686 ; 5223)$ & $A$ & 0.725 & 24 & $(-636 ; 685)$ & \\
\hline CP-16 & 22 & 3779 & $(3020 ; 4539)$ & $A$ & 3678 & $(2899 ; 4457)$ & $A$ & 0.744 & 102 & $(-537 ; 740)$ & \\
\hline HP-35 & 29 & 4216 & $(3661 ; 4772)$ & $A$ & 3768 & $(3209 ; 4327)$ & $A$ & 0.063 & 449 & $(-27 ; 924)$ & \\
\hline HP-40 & 24 & 4210 & $(3289 ; 5131)$ & $A$ & 3662 & $(2879 ; 4445)$ & $A$ & 0.125 & 322 & $(-238 ; 883)$ & \\
\hline Intervention & $N$ & \multicolumn{3}{|c|}{$\Delta Z_{\text {baseline,DC }}($ vol $\% \times \mu \mathrm{m})$} & \multicolumn{3}{|c|}{$\Delta Z_{\mathrm{pH}-\mathrm{cycling}, \mathrm{DC}}(\mathrm{vol} \% \times \mu \mathrm{m})$} & $p^{*}$ & \multicolumn{2}{|c|}{$\Delta \Delta Z_{\mathrm{DC}}(\operatorname{vol} \% \times \mu \mathrm{m})$} & \\
\hline NBl-NBr & 28 & 4690 & $(4012 ; 5367)$ & $a$ & 6041 & $(5219 ; 6863)$ & $a$ & 0.006 & -1446 & $(-2451 ;-441)$ & \\
\hline $\mathrm{NBl}$ & 32 & 4645 & $(3890 ; 5400)$ & $a$ & 5215 & $(4372 ; 6058)$ & $a$ & 0.184 & -605 & $(-1480 ; 271)$ & \\
\hline HР-6 & 27 & 4642 & $(3863 ; 5421)$ & $a$ & 5561 & $(4654 ; 6467)$ & $a$ & 0.037 & -771 & $(-1702 ; 161)$ & \\
\hline CP-16 & 27 & 4568 & $(3701 ; 5435)$ & $a$ & 4807 & $(3932 ; 5682)$ & $a$ & 0.620 & -275 & $(-1284 ; 734)$ & \\
\hline HP-35 & 31 & 4223 & $(3507 ; 4938)$ & $a$ & 4999 & $(4261 ; 5737)$ & $a$ & 0.019 & -776 & $(-1417 ;-135)$ & \\
\hline HP-40 & 29 & 4719 & $(3746 ; 5691)$ & $a$ & 4585 & $(3590 ; 5579)$ & $a$ & 0.801 & -18 & $(-1103 ; 1067)$ & \\
\hline
\end{tabular}

*Italicized $p$ values indicate significant differences in mineral losses before and after pH-cycling (two-tailed paired $t$ test). Different letters indicate significant differences between treatments among infiltrated (DI, large caps) and non-infiltrated (DC, small caps) demineralized specimens ( $p<0.05$; Bonferroni post hoc test). Negative $\Delta \Delta Z$ values indicate demineralization, and positive $\Delta \Delta Z$ values indicate remineralization

significant difference could be observed between infiltrated and non-infiltrated lesions as well as (non-infiltrated) sound enamel [29]. In the third study, no significant difference in $\Delta E$ values could be observed between infiltrated lesions and infiltrated sound enamel [4]. In that study, it could also be observed that color differences of infiltrated lesions increased relatively when compared to non-infiltrated lesions or sound enamel. Furthermore, in one study, it was observed that after staining, infiltrated lesions showed significantly higher $\Delta E$ values than lesions which were stored in artificial saliva and treated with sodium fluoride daily for eight days before staining [29]. However, in that study, bovine enamel was etched with $\mathrm{HCl}$ for $120 \mathrm{~s}$ instead of phosphoric acid gel [21] and it was not reported weather the oxygen inhibition layer after infiltration was removed.

By infiltrating the microporosities of the lesions, they were penetrated with a low-viscosity resin. Although resin-based materials are widely used in aesthetic restorations, they are subjected to color alteration over time. For example, triethylene glycol dimethacrylate (TEGDMA) - the main component of the infiltrant - is presumed to increase water absorption [30, 31] and hinder color stability [32]. Consequently, it might be speculated that, if the resin material is able to absorb water, it is also able to absorb other fluids, resulting in the alteration of color [33]. In recent studies on the color stability of infiltrated lesions, polishing after infiltration significantly increased the resistance to subsequent discolorations [4, 34]. However, the appearance of already discolored sound enamel and infiltrated lesions could not be recovered by polishing alone [29]. No significant difference in $\Delta L$ - and $\Delta E$ values before and after polishing could be observed.
Interestingly, the appearance of discolored sound enamel and infiltrated lesions could recently be recovered by bleaching - another (non-invasive) aesthetic solution to whiten teeth and to remove discoloration [12]. Although, firstly, bovine enamel were etched with $\mathrm{HCl}$ instead of phosphoric acid gel [21] and, secondly, not reporting lesions depths of the lesions, no significant difference in the CIE $L^{*} a^{*} b^{*}$ values were observed between infiltrated demineralized and sound enamel. The results are in agreement with the present study. Bleaching significantly increased $L$ values of infiltrated demineralized as well as infiltrated sound enamel. Furthermore, colorimetric differences $(\Delta E)$ between infiltrated demineralized and infiltrated sound enamel after infiltration and after bleaching did not significantly differ, indicating that the visual appearance could be recovered.

No significant difference in the bleaching effects between the $6 \% \mathrm{HP}$-based and 16\% CP-based agents for at-home bleaching could be observed. Although this result seems to be consistent with previous in vivo studies [35, 36], a recent meta-analysis on HP and CP for at-home bleaching revealed that CP-based agents showed slightly significantly higher color changes than HP-based ones [10]. Interestingly, the active whitening component in both bleaching agents is the same: $\mathrm{HP}-a 10 \% \mathrm{CP}$ gel consists of roughly $3.5 \% \mathrm{HP}$ and $6.5 \%$ urea [10]. Furthermore, the concentrations of the active HP were higher in HP-based than in CP-based agents. However, it was speculated that the release of HP in tray-delivered CPbased agents is slower than in HP-based ones [37]. Consequently, HP for oxidation in CP-based agents is available over a longer time than in HP-based agents, resulting in higher color changes [10]. It might, furthermore, be 
speculated that in the present in vitro study, both bleaching agents (HP and $\mathrm{CP}$ ) whitened the analyzed surfaces to the maximum. The visual appearance of infiltrated demineralized and sound enamel surfaces was successfully recovered and a further whitening effect of surfaces being infiltrated with a low viscosity resin was not feasible. Consequently, under the present in vitro setting, the presumed slightly higher whitening effect of CP-based agents was not expectable and not representable.

In the previous studies on color stability of infiltrated surfaces, specimens were stained for either 10 [34] or 14 days [12]. Although surfaces significantly discolored within these periods, it was not reported if pigments of red wine-coffee mixtures were deposited as surface precipitates on the enamel surfaces or incorporated into the enamel surfaces. In contrast, in the present study, specimens were stained within 70 days (as performed before [22]) and it could be shown that pigments were not only deposited on the surface but were also incorporated up to a depth of $99 \mu \mathrm{m}$ in both sound and demineralized non-infiltrated and up to a depth of $47 \mu \mathrm{m}$ in sound and demineralized infiltrated enamel (data not presented).

A few studies investigated the influence of staining $[12,29$, 34] and bleaching [12] on the color stability of infiltrated demineralized and sound enamel. However, the influence of bleaching on the caries-arresting effects of the infiltration has not been analyzed until now. In the present study, no significant change in mineral content for infiltrated surfaces during $\mathrm{pH}$-cycling and no effect of the bleaching gels on the caries inhibition by infiltration could be observed. This is in agreement with previous non-bleaching $\mathrm{pH}$-cycling studies $[5,38]$. However, after infiltration, specimens were stored in remineralization solution for 70 days, before they were $\mathrm{pH}$ cycled for 28 days. Consequently, it might be speculated that the present in vitro protocol resulted in relative neutral conditions and that no (significant) changes in mineral loss in infiltrated enamel were observed due to the neutral conditions. Nevertheless, in non-infiltrated demineralized enamel, a significant demineralization could be observed in NBl-NBr (no bleaching as well as no brushing during $\mathrm{pH}$-cycling), whereas in $\mathrm{NBl}$ (no bleaching but brushing during $\mathrm{pH}$-cycling), no significant demineralization could be observed, indicating netto-demineralizing conditions during $\mathrm{pH}$-cycling.

In the present study, a significant demineralization could not only be observed in NBl-NBr but also for acidic bleaching agents (HP-6 and HP-35). Contrastingly, no significant increase could be observed for the neutral bleaching agents (CP-16 and HP-40). These results are in agreement with previous studies showing $\mathrm{pH}$-depending demineralization [39], erosively induced demineralization [40] and changes in the surface morphology [41]. In contrast, other studies showed no correlation between the $\mathrm{pH}$ of bleaching agents and tooth wear [42], or between $\mathrm{pH}$ and enamel demineralization [43, 44]. Interestingly, one study indicated that bleaching agents might induce $\mathrm{pH}$-depending enamel morphology alterations in vitro but that the observed demineralizing effect might be irrelevant in in situ conditions [45]. Since, firstly, the present study did not primarily analyze the influence of the $\mathrm{pH}$ of bleaching agents, secondly, the in vitro models as well as the outcomes in the cited studies and the present varied widely and, thirdly, the observation that under clinical conditions the observed effects might be masked, the clinical significance of the bleaching agents' $\mathrm{pH}$ remains unclear.

This study is subject to a number of limitations. First, bovine enamel instead of human enamel was used. Although several studies demonstrated that human and bovine enamel react similarly, slight differences between both substrates were also reported [46]. Second, due to the bovine artificial caries lesions, the etching procedure had to be modified [21]. Thus, an etching procedure with phosphoric acid for $5 \mathrm{~s}$ was chosen (instead $120 \mathrm{~s}$ using $\mathrm{HCl}$ as instructed by the manufacturer), as this protocol was already tested in previous studies using bovine teeth $[4,5,21]$. Third, demineralized lesions with mean lesion depths of $171 \mu \mathrm{m}$ were used to analyze the bleaching effects. From a clinical point of view, they would probably be difficult to detect in vivo as discussed previously [20]. However, the initiation and progression of enamel caries lesions seems to be extremely slow and anti-caries effects are assumed to be limited to the outer 150-200 $\mu \mathrm{m}$ of the lesion (at deeper levels, no difference was observed compared with placebo). Fourth, a pH-cycling model is a chemical caries model without any biofilm. Thus, no antimicrobial interferences in the staining (or bleaching) could be analyzed. Fifth, for colorimetric analysis the sound non-infiltrated surfaces (SC) served as "intra-specimen" reference to analyze the change in $\Delta E$ and $\Delta L$ values. However, these surfaces were stained as well. Thus, to objectively describe the darkening effect of the staining and the whitening effect of the bleaching procedure, the colorimetric analysis had to be modified. For these analyses, the gray card instead of SC was used as specimen reference to calculate $\Delta E$ and $\Delta L$ values. Although this modification was also performed previously [4], absolute colorimetric results and measured color differences between different time points should be interpreted with caution.

Under the $\mathrm{pH}$-cycling conditions chosen, the tested bleaching agents could successfully recover the visual appearance of infiltrated and non-infiltrated stained caries-like enamel lesions. Furthermore, the masking and the caries-arresting effects of infiltrated lesions remained stable after bleaching and $\mathrm{pH}$-cycling.

Acknowledgments We thank Klaus Mussler and the whole team of the scientific construction laboratory of the RWTH Aachen University. This study was conducted as part of the doctoral thesis of E.E.J.

Author contributions R.J.W., H.M.-L., and E.E.J. designed and planned the study; R.J.W. and H.M.-L. supervised the study; E.E.J. prepared the specimens and performed the measurements; E.E.J and R.J.W. performed 
the statistical analysis; E.E.J. wrote the manuscript and R.J.W., H.M.-L. and M.E.-O. reviewed the manuscript.

Funding Open Access funding enabled and organized by Projekt DEAL. This study was funded by the authors and their institution. We thank Ultradent Products (USA), FGM (Brazil), and DMG (Germany) for providing their products.

Data availability Data can be requested from the authors.

\section{Compliance with ethical standards}

Conflict of interest H.M.-L is appointed as inventor for patents of an infiltration technique for dental caries lesions, held by CharitéUniversitätsmedizin Berlin, and receives royalties from DMG, the manufacturer of Icon.

E.E.J., M.E.-O., and R.J.W. declare no conflicts of interests.

Ethical approval This article does not contain any studies with human participants or animals performed by any of the authors.

Informed consent For this type of study, formal consent is not required.

Disclaimer The manufactures had no role in design, conduct, evaluation, interpretation of the study, or in writing the manuscript.

Open Access This article is licensed under a Creative Commons Attribution 4.0 International License, which permits use, sharing, adaptation, distribution and reproduction in any medium or format, as long as you give appropriate credit to the original author(s) and the source, provide a link to the Creative Commons licence, and indicate if changes were made. The images or other third party material in this article are included in the article's Creative Commons licence, unless indicated otherwise in a credit line to the material. If material is not included in the article's Creative Commons licence and your intended use is not permitted by statutory regulation or exceeds the permitted use, you will need to obtain permission directly from the copyright holder. To view a copy of this licence, visit http://creativecommons.org/licenses/by/4.0/.

\section{References}

1. Kose C, Calixto AL, Bauer JR, Reis A, Loguercio AD (2016) Comparison of the effects of in-office bleaching times on whitening and tooth sensitivity: a single blind, randomized clinical trial. Oper Dent 41:138-145. https://doi.org/10.2341/15-085-c

2. Huang GJ, Roloff-Chiang B, Mills BE, Shalchi S, Spiekerman C, Korpak AM, Starrett JL, Greenlee GM, Drangsholt RJ, Matunas JC (2013) Effectiveness of MI Paste Plus and PreviDent fluoride varnish for treatment of white spot lesions: a randomized controlled trial. Am J Orthod Dentofacial Orthop 143:31-41. https://doi.org/ 10.1016/j.ajodo.2012.09.007

3. Shafi I (2008) Fluoride varnish reduces white spot lesions during orthodontic treatment. Evid Based Dent 9:81. https://doi.org/10. 1038/sj.ebd.6400599

4. Paris S, Schwendicke F, Keltsch J, Dorfer C, Meyer-Lueckel H (2013) Masking of white spot lesions by resin infiltration in vitro. J Dent 41(Suppl 5):e28-e34. https://doi.org/10.1016/j.jdent.2013. 04.003

5. Wierichs RJ, Kogel J, Lausch J, Esteves-Oliveira M, MeyerLueckel H (2017) Effects of self-assembling peptide P11-4, fluorides, and caries infiltration on artificial enamel caries lesions in vitro. Caries Res 51:451-459. https://doi.org/10.1159/ 000477215

6. Knosel M, Eckstein A, Helms HJ (2019) Long-term follow-up of camouflage effects following resin infiltration of post orthodontic white-spot lesions in vivo. Angle Orthod 89:33-39. https://doi.org/ 10.2319/052118-383.1

7. Kobbe C, Fritz U, Wierichs RJ, Meyer-Lueckel H (2019) Evaluation of the value of re-wetting prior to resin infiltration of post-orthodontic caries lesions. J Dent 91:103243. https://doi.org/ 10.1016/j.jdent.2019.103243

8. Rey N, Benbachir N, Bortolotto T, Krejci I (2014) Evaluation of the staining potential of a caries infiltrant in comparison to other products. Dent Mater J 33:86-91

9. Majeed A, Farooq I, Grobler SR, Rossouw RJ (2015) Toothbleaching: a review of the efficacy and adverse effects of various tooth whitening products. J Coll Physicians Surg Pak 25:891-896

10. Luque-Martinez I, Reis A, Schroeder M, Munoz MA, Loguercio AD, Masterson D, Maia LC (2016) Comparison of efficacy of traydelivered carbamide and hydrogen peroxide for at-home bleaching: a systematic review and meta-analysis. Clin Oral Investig 20:14191433. https://doi.org/10.1007/s00784-016-1863-7

11. Demarco FF, Conde MC, Ely C, Torre EN, Costa JR, Fernandez MR, Tarquinio SB (2013) Preferences on vital and nonvital tooth bleaching: a survey among dentists from a city of southern Brazil. Braz Dent J 24:527-531. https://doi.org/10.1590/01036440201302152

12. Araujo GS, Naufel FS, Alonso RC, Lima DA, Puppin-Rontani RM (2015) Influence of staining solution and bleaching on color stability of resin used for caries infiltration. Oper Dent 40:E250-E256. https://doi.org/10.2341/14-290-L

13. Torres CRG, Zanatta RF, Fonseca BM, Borges AB (2019) Fluorescence properties of demineralized enamel after resin infiltration and dental bleaching. Am J Dent 32:43-46

14. Turker SB, Biskin T (2002) The effect of bleaching agents on the microhardness of dental aesthetic restorative materials. J Oral Rehabil 29:657-661. https://doi.org/10.1046/j.1365-2842.2002. 00896.x

15. Moraes RR, Marimon JL, Schneider LF, Correr Sobrinho L, Camacho GB, Bueno M (2006) Carbamide peroxide bleaching agents: effects on surface roughness of enamel, composite and porcelain. Clin Oral Investig 10:23-28. https://doi.org/10.1007/ s00784-005-0016-1

16. Polydorou O, Hellwig E, Auschill TM (2006) The effect of different bleaching agents on the surface texture of restorative materials. Oper Dent 31:473-480. https://doi.org/10.2341/05-75

17. Dutra RA, Branco JR, Alvim HH, Poletto LT, Albuquerque RC (2009) Effect of hydrogen peroxide topical application on the enamel and composite resin surfaces and interface. Indian J Dent Res 20:65-70. https://doi.org/10.4103/0970-9290.49074

18. Wierichs RJ, Westphal S, Lausch J, Meyer-Lueckel H, EstevesOliveira M (2018) Influence of highly concentrated fluoride dentifrices on remineralization characteristics of enamel in vitro. Clin Oral Investig 22:2325-2334. https://doi.org/10.1007/s00784-0182333-1

19. Buskes JA, Christoffersen J, Arends J (1985) Lesion formation and lesion remineralization in enamel under constant composition conditions. A new technique with applications. Caries Res 19:490-496

20. Wierichs RJ, Lausch J, Meyer-Lueckel H, Esteves-Oliveira M (2016) Re- and demineralization characteristics of enamel depending on baseline mineral loss and lesion depth in situ. Caries Res 50: 141-150. https://doi.org/10.1159/000444537

21. Gray GB, Shellis P (2002) Infiltration of resin into white spot caries-like lesions of enamel: an in vitro study. Eur J Prosthodont Restor Dent 10:27-32 
22. Attin T, Manolakis A, Buchalla W, Hannig C (2003) Influence of tea on intrinsic colour of previously bleached enamel. J Oral Rehabil 30:488-494

23. Lugo-Varillas JG, Tinedo-López PL, Watanabe-Oshiro G, CorreaMedina A, Álvarez-Vidigal E, Hermoza-Novoa M (2020) Influencia del nivel de $\mathrm{pH}$ de geles blanqueadores en la rugosidad superficial del esmalte bovino. Odovtos Int J Dent Sci 22:100-111

24. Wiegand A, Vollmer D, Foitzik M, Attin R, Attin T (2005) Efficacy of different whitening modalities on bovine enamel and dentin. Clin Oral Investig 9:91-97. https://doi.org/10.1007/s00784-004-0291-2

25. Wierichs RJ, Rupp K, Meyer-Lueckel H, Apel C, Esteves-Oliveira M (2020) Effects of dentifrices differing in fluoride content on remineralization characteristics of dentin in vitro. Caries Res 54: 75-86. https://doi.org/10.1159/000504165

26. Esteves-Oliveira M, Santos NM, Meyer-Lueckel H, Wierichs RJ, Rodrigues JA (2017) Caries-preventive effect of anti-erosive and nano-hydroxyapatite-containing toothpastes in vitro. Clin Oral Investig 21:291-300. https://doi.org/10.1007/s00784-016-1789-0

27. Wierichs RJ, Musiol J, Erdwey D, Esteves-Oliveira M, Apel C, Meyer-Lueckel H (2020) Re- and demineralization characteristics of dentin depending on fluoride application and baseline characteristics in situ. J Dent 94:103305. https://doi.org/10.1016/j.jdent. 2020.103305

28. Walther C, Kreibohm M, Paris S, Meyer-Lueckel H, Tschoppe P, Wierichs RJ (2019) Effect of NaF, AmF, KF gels and NaF toothpaste combined with a saliva substitute on dentin lesions in vitro. Clin Oral Investig 23:2489-2496. https://doi.org/10.1007/s00784018-2687-4

29. Cohen-Carneiro F, Pascareli AM, Christino MR, Vale HF, Pontes DG (2014) Color stability of carious incipient lesions located in enamel and treated with resin infiltration or remineralization. Int $\mathbf{J}$ Paediatr Dent 24:277-285. https://doi.org/10.1111/ipd.12071

30. Park J, Eslick J, Ye Q, Misra A, Spencer P (2011) The influence of chemical structure on the properties in methacrylate-based dentin adhesives. Dent Mater 27:1086-1093. https://doi.org/10.1016/j. dental.2011.07.011

31. Sideridou ID, Karabela MM, Bikiaris DN (2007) Aging studies of light cured dimethacrylate-based dental resins and a resin composite in water or ethanol/water. Dent Mater 23:1142-1149. https://doi. org/10.1016/j.dental.2006.06.049

32. Janda R, Roulet JF, Latta M, Ruttermann S (2007) Water sorption and solubility of contemporary resin-based filling materials. $\mathrm{J}$ Biomed Mater Res B Appl Biomater 82:545-551. https://doi.org/ 10.1002/jbm.b.30760

33. Fontes ST, Fernandez MR, de Moura CM, Meireles SS (2009) Color stability of a nanofill composite: effect of different immersion media. J Appl Oral Sci 17:388-391. https://doi.org/10.1590/s167877572009000500007

34. Borges A, Caneppele T, Luz M, Pucci C, Torres C (2014) Color stability of resin used for caries infiltration after exposure to different staining solutions. Oper Dent 39:433-440. https://doi. org/10.2341/13-150-L

35. Mokhlis GR, Matis BA, Cochran MA, Eckert GJ (2000) A clinical evaluation of carbamide peroxide and hydrogen peroxide whitening agents during daytime use. J Am Dent Assoc 131:1269-1277. https://doi.org/10.14219/jada.archive.2000.0380

36. Kowitz GM, Rustogi KN, Wong R, Curtis JP, Wieckowski SE (1991) The influence of chemical structure on the properties in methacrylate-based dentin adhesives (abstract 1268). J Dent Res 70:424

37. Matis BA, Yousef M, Cochran MA, Eckert GJ (2002) Degradation of bleaching gels in vivo as a function of tray design and carbamide peroxide concentration. Oper Dent 27:12-18

38. Paris S, Meyer-Lueckel H, Kielbassa AM (2007) Resin infiltration of natural caries lesions. J Dent Res 86:662-666. https://doi.org/10. $1177 / 154405910708600715$

39. Price RB, Sedarous M, Hiltz GS (2000) The pH of tooth-whitening products. J Can Dent Assoc 66:421-426

40. Attin T, Kocabiyik M, Buchalla W, Hannig C, Becker K (2003) Susceptibility of enamel surfaces to demineralization after application of fluoridated carbamide peroxide gels. Caries Res 37:93-99. https://doi.org/10.1159/000069015

41. Xu B, Li Q, Wang Y (2011) Effects of $\mathrm{pH}$ values of hydrogen peroxide bleaching agents on enamel surface properties. Oper Dent 36:554-562. https://doi.org/10.2341/11-045-1

42. Soares AF, Bombonatti JF, Alencar MS, Consolmagno EC, Honorio HM, Mondelli RF (2016) Influence of pH, bleaching agents, and acid etching on surface wear of bovine enamel. J Appl Oral Sci 24:24-30. https://doi.org/10.1590/1678775720150281

43. Jurema ALB, de Souza MY, Torres CRG, Borges AB, Caneppele TMF (2018) Effect of pH on whitening efficacy of $35 \%$ hydrogen peroxide and enamel microhardness. J Esthet Restor Dent 30:E39 E44. https://doi.org/10.1111/jerd.12367

44. Acuna ED, Parreiras SO, Favoreto MW, Cruz GP, Gomes A, Borges CPF, Loguercio AD, Reis A (2019) In-office bleaching with a commercial $40 \%$ hydrogen peroxide gel modified to have different $\mathrm{pHs:}$ Color change, surface morphology, and penetration of hydrogen peroxide into the pulp chamber. J Esthet Restor Dent. https://doi.org/10.1111/jerd.12453

45. Sa Y, Sun L, Wang Z, Ma X, Liang S, Xing W, Jiang T, Wang Y (2013) Effects of two in-office bleaching agents with different $\mathrm{pH}$ on the structure of human enamel: an in situ and in vitro study. Oper Dent 38:100-110. https://doi.org/10.2341/11-173-L

46. Mellberg JR (1992) Hard-tissue substrates for evaluation of cariogenic and anti-cariogenic activity in situ. J Dent Res 71 Spec No: 913-9. https://doi.org/10.1177/002203459207100s25

Publisher's note Springer Nature remains neutral with regard to jurisdictional claims in published maps and institutional affiliations. 